Meijers, M.C., Potappel, A., Kloek, C. Hartman, T. olde, Spreeuwenberg, P., Dulmen, S. van,

Noordman, J. Patient Education and Counseling: 2020, 103(6), p. 1168-1175

Postprint version $\quad: \quad 1.0$

Journal website $\quad:$ https://www.sciencedirect.com/science/article/abs/pii/S0738399120300 434?via\%3Dihub

Pubmed link $\quad$ : https://pubmed.ncbi.nlm.nih.gov/31983476

DOI

: 10.1016/j.pec.2020.01.016

This is a Nivel certified Post Print, more info at nivel.nl

\title{
Shifts in patients' question-asking behaviour between 2007 and 2016: An observational study of video- recorded general practice consultations
}

\author{
Maartje C. Meijers ${ }^{\mathrm{a}, \mathrm{b}, \mathrm{c},{ }^{*},}$ Amy Potappel ${ }^{\mathrm{a}}$, Corelien Kloek $^{\mathrm{d}}$, Tim olde Hartman ${ }^{\mathrm{e}}$,
} Peter Spreeuwenberg ${ }^{a}$, Sandra van Dulmen ${ }^{a, f, g}$, Janneke Noordman ${ }^{a}$

a Nivel, Netherlands institute for health services research, Utrecht, the Netherlands

b Health, Medical and Neuropsychology Unit, Institute of Psychology, Leiden University, Leiden, the Netherlands

c Department of Medical Psychology, Academic Medical Center, University of Amsterdam, the Netherlands

d Research Group Innovation of Human Movement Care, HU University of Applied Sciences, Utrecht, the Netherlands

e Department of Primary and Community Care, Donders Institute for Brain, Cognition and Behaviour, Radboud university medical center, Nijmegen, the Netherlands

f Radboud university medical center, Radboud Institute for Health Sciences, Department of Primary and Community Care, Nijmegen, the Netherlands

g Faculty of Health and Social Sciences, University of South-Eastern Norway, Drammen, Norway

\begin{abstract}
A B S T R A C T
Objective: To gain insight into patient participation in general practice by examining if and how patients' question-asking behaviour has changed over the years (2007-2016). Methods: A random set of real-life video-recorded consultations collected in 2015-2016 ( $n=437$ ) was observed and compared with that of a former study in 2007-2008 ( $n=$ 533). Patients' question-asking behaviour was coded using an adapted RIAS protocol containing six categories: medical condition/therapeutic regimen; psychosocial; social context; lifestyle; ask for opinion doctor; practical. GPs and patients completed questionnaires about their background characteristics. Data were analysed using multilevel analysis.

Results: Patients asked fewer questions in 2016 than in 2007. The type of questionasking behaviour changed significantly: in particular medical questions decreased while practical questions increased. Less educated patients asked significantly more practical questions than higher educated patients.
\end{abstract}


Meijers, M.C., Potappel, A., Kloek, C. Hartman, T. olde, Spreeuwenberg, P., Dulmen, S. van, Noordman, J. Patient Education and Counseling: 2020, 103(6), p. 1168-1175

Conclusion: Contrary to our expectations, patients' question-asking has decreased in 2016 compared to 2007, while the average consultation length has increased. The type of questions shifted from medical to practical, especially in less educated patients. It seems that GPs' professional role has expanded over time, since patients nowadays ask their GP more non-medical questions. Practice implications: GPs probably could continue facilitating patient involvement by more frequently using partnership-building and supportive communication

\section{Introduction}

Patient participation is an important concept in contemporary healthcare and particularly within the medical discourse, as more active patient participation contributes to improved health outcomes and quality of care [1-3]. Active patients are more likely to elicit useful information from their general practitioner (GP) $[4,5]$, which consequently leads to an increase in self-efficacy and a greater sense of control over their care [6,7]. Moreover, the patient's communication style can have a powerful effect on GPs behaviour and beliefs. For example, GPs typically are more informative, accommodating, and supportive when patients ask questions, make requests, offer opinions, and express their fears and concerns [8-12].

Patient question-asking can be regarded as operationalisation of patient participation during the medical dialogue. As such, a study on question-asking behaviour provides insight into the GPpatient communication process and the level of consultationspecific patient participation [13]. In the Netherlands, GPs are the point of entry for people to health care (gatekeepers). Specialists and hospital care can only be accessed after referral by the GP. Health insurance is mandatory, which covers a standard benefit package including primary care delivered by GPs, and all Dutch residents are registered in one general practice. Most GPs work in small practices (2-5 practitioners together with practice nurses (specialized in chronic diseases and mental health) located close to the community. Many GPs employ nurses (specialized in chronic diseases) and primary care psychologists, and there is close collaboration with other primary care disciplines. Since the 2006 healthcare reform within the Netherlands (i.e. introduction of a uniform health insurance system and managed competition between health insurers), patient participation and patient choice have become important policy priorities [3]. Next to their formal representation in councils and other bodies patients are now empowered to be in control of their own care in accordance with their needs and preferences. Given the current measures by the Dutch Ministry of Health, Dutch Patients Federations, professional bodies and health insurers, an increase in patients' question-asking can be expected, as most modern patients are said to want more information and to be more actively engaged in the medical consultation $[1,8,14]$.

Several other studies have indicated that patients' questionasking has also increased through the emergence of the internet and changes in the power balance within the patient-provider relationship $[1,8,13]$. Furthermore, given the increased emphasis on people's individual responsibility for their health, one might also expect an increase in patients' question-asking behaviour in daily general practice [14]. Despite this expectation, a previous study among hypertension patients revealed a shift towards a more business-like, task-oriented GP communication pattern, with relatively few patients being active and critical consumers [15]. Recent studies on the number and type of patients' questions in everyday general practice are lacking as are studies investigating changes over time. Such insights might help policymakers to assess if their measures have already been productive and inform providers if they allow patients enough room for asking questions. The aim of the present study is to gain insight into patient participation in general practice by examining if and how patients' question-asking behaviour has changed over the years (2007-2016). 
Meijers, M.C., Potappel, A., Kloek, C. Hartman, T. olde, Spreeuwenberg, P., Dulmen, S. van, Noordman, J. Patient Education and Counseling: 2020, 103(6), p. 1168-1175

\section{Methods}

\subsection{Study design}

An observational study using a recent dataset of video-recorded routine GP consultations [16] was performed. The video-recorded consultations were analysed to identify the number and type of patients' questions. In order to analyse changes over time, the results were compared with those using data from a previous study on patients' question-asking behaviour which had a comparable design [17]. Video-recording is proven to be a valid method for examining the doctor-patient communication as the influence of the video-recorder on the participants' behaviour is marginal [18].

\subsection{Setting and procedure}

For the 2015-2016 part of the dataset, video-recorded consultations were merged from two datasets. One dataset was collected in 2015 in several primary care practices in the eastern part of the Netherlands [16]. This dataset included consultations from $20 \mathrm{GPs}$ (response rate was $56 \%$ ). Of the 509 eligible patients, 393 agreed to participate (77 \%) (Fig. 1). Two consultations were not recorded on video due to technological errors. The other dataset was collected in 2016 whereby another 8 GPs participated (response rate was $18 \%$ ), spread throughout the Netherlands. These GPs were approached via the network of the researchers and participation in earlier studies from Nivel (Netherlands institute for health services research) and Radboudumc (Radboud university medical center). Of the 122 eligible patients, 77 agreed to participate (63\%). For the present study, we merged the 2015-2016 video-recorded consultations which resulted in a final dataset with 28 GPs. The number of video-recorded consultations per GP ranged from 9 to 29. In total 470 consultations were recorded. Before analyses, missing values (i.e. due to missings on background characteristics of patients) were removed which resulted in a total amount of 437 consultations for 2015-2016.

For the 2007-2008 study [17], 40 GPs from 20 practices agreed to participate (response rate was $44 \%$ ), which were all members of the Nivel Primary Care Database (Nivel Zorgregistraties eerstelijn) consisting of - at the time - 180 Dutch GPs and 340000 patients, spread throughout the Netherlands [19]. In total 808 consultations were recorded (patient response $78 \%$ ). Missing values (i.e. due to missings on background characteristics of patients) were removed which resulted in a total amount of 533 consultations from 2007 to 2008 (Fig. 1).

\section{[Figure 1]}

All video-recordings were made by an unmanned camera during one or two random days per GP. Before each consultation, a researcher approached the patient in the waiting room and asked for written consent to video-record their consultation. Written informed consent was obtained from all participants. It was stressed that participants could withdraw their consent at any time and it would not affect their standard of care. GPs and patients completed questionnaires about their background characteristics (i.e. age, sex and education). Also, patients' symptoms during consultations were registered by the GPs according to the International Classification of Primary Care (ICPC). Only the main complaint (ICPC) was registered even though consultations may include various complaints. The patients and GPs were aware that the study focused on communication, but they were not aware of the focus on patients' question-asking behaviour. Both studies adhered to the Dutch privacy legislation, approved by the Dutch Data Protection Authority. According to Dutch legislation, approval by a medical ethics committee was not required for these observational studies. 
Meijers, M.C., Potappel, A., Kloek, C. Hartman, T. olde, Spreeuwenberg, P., Dulmen, S. van, Noordman, J. Patient Education and Counseling: 2020, 103(6), p. 1168-1175

\subsection{Participants}

Patients who did not speak Dutch well and patients under 18 years old were excluded. Participating patients were videorecorded from behind and were therefore unrecognizable, while the GP was clearly visible.

\section{[Table 1]}

\subsection{Observations}

Three researchers observed the video consultations; one third from the total amount of consultations per observer. All coders were trained using an adapted RIAS protocol (see below), to allow for a comparison with the coding in 2007-2008 and in order to align the manner of coding. At first, five consultations were observed together to get used to the observation protocol by which disagreements were discussed and resolved. We repeated this once, whereupon we agreed that our coding manner was sufficiently equivalent. To ensure reliability, all observers ( $M M, A P, C K$ ) reviewed $10 \%(N=48)$ of each other's coding. Inter-rater reliability between the observers was calculated with Cohen's kappa and indicated substantial inter-rater agreement (range: 66.67-95.83) [20] (Table 1). Also, for each video-recording, the duration of the consultation was registered. The first spoken word within the physician-patient encounter in the consulting room was seen as the start of a consultation, the last spoken word as the end of the consultation. The time between these two points was regarded as the consultation length (only between physician and patient). The physical exam was included in the visit length but it was out of view and was not part of the analysis. For analysis purpose, the nature of complaints (ICPC chapters coding) was aggregated into 5 chapters (Table 2).

\section{Table 2}

\section{Measuring patients' question-asking behaviour}

Patients' question-asking behaviour was coded using the RIAS (Roter Interaction Analysis System), a widely-used international observation system for coding every utterance in medical interactions with proven validity and reliability [21,22]. For the scope of this study, the following categories were used: (1) medical condition/therapeutic regimen, (2) psychosocial, (3) social context, (4) lifestyle, (5) ask for opinion doctor, and (6) practical (mainly financial and requests for services). Per category, the number of questions was registered as well. Each single sentence was counted as a question and during one consultation several categories could be coded, e.g. two medical questions, one lifestyle question and one practical question.

\section{[Table 2] [Table 3]}

\subsection{Statistical analysis}

Descriptive analyses were used to describe GP, patient, and consultation characteristics and the type and number of patients' question. To account for clustering of patients within GPs, the type of patients' question-asking behaviour (including year of measurement, sex and age of patients and GPs, educational level of patients, the nature of complaints (ICPC), and consultation length) was analysed using logistic multilevel analysis (with patients (Level 1) nested within GPs (Level 2)). With respect to the number of questions, Poisson regression was used. Analyses were built up similarly. Model 1 included patients' question-asking compared over time (with 2007 as reference year compared to 2016). In model 2 we added the following variables: the patient's age, the patient's sex, the GP's age, the GP's sex, and patients' educational level. In model 3 we added: the nature of 
Meijers, M.C., Potappel, A., Kloek, C. Hartman, T. olde, Spreeuwenberg, P., Dulmen, S. van, Noordman, J. Patient Education and Counseling: 2020, 103(6), p. 1168-1175

complaints (ICPC) and consultation length. Data were analysed using Stata version 14 (Stata, 2015) [23].

\section{Results}

\subsection{Sample characteristics}

In 2015-2016, of the 28 participating GPs 12 were male and 16 were female, and GPs were middle-aged (mean $=47$ years, range $=31-69$ ). The majority of primary health care settings were in the east of the country; 13 practices were located in the city and 15 practices in rural areas. The 437 patients had a mean age of 54 years (range 18-90). The greater part was female (57 \%) and more than one third of the patients had a higher or university education (35\%) (Table 3). In 2007-2008, of the 40 participating GPs, 26 were male and 14 were female, and GPs were middle-aged (mean = 51 years, range $=40-62$ ). Data were collected in several primary care practices spread throughout the Netherlands; 27 practices were located in the city and 13 in more rural areas. The 533 patients had a mean age of 52 years (range 18-87). The greater part was female (60 \%) and $22 \%$ had a higher or university education (Table 3). Overall, the GPs who participated represent Dutch GPs regarding age, practice form (solo -, duo-, group practice or health centre) and number of days worked and the educational level of our sample corresponds with the general educational level among the population in the Netherlands.

In both datasets, most patients' symptoms were related to the ICPC chapters 1: General and unspecified diseases (fatigue, generalized pain) including Eyes (conjunctivitis, corpus alienum), Ears (otitis media acuta, impaired hearing), Dermatological diseases (fungus, eczema), and the Respiratory tract (coughing, pneumoniae).

The consultations lasted significantly longer in 2015-2016 (13.4 min) than in 2007-2008 (10.7 min) (Table 3).

\subsection{Patients' question-asking behaviour}

The total number of questions asked by patients was in 2015-2016 $(\mathrm{N}=475$, Mean $=2.8)$ significantly lower than in 2007-2008 ( $\mathrm{N}=654$, Mean $=3.8$ ) (Coef. $-0.46 ;$ SD $0.10 ; 95 \% \mathrm{Cl}-0.66$ to $0.20 ; \mathrm{P}=0.00$ ). While medical, psychosocial and social context questions had significantly decreased compared to 2007, practical questions (mainly financial and requests for services) significantly increased (see Table 4). Medical questions still remained the top question category (Table 4). Lifestyle-related questions and the amount of 'ask for opinion'-questions remained the same (Table 4). In Table 5 the types of questions are illustrated by quotes.

\section{[Table 4] [Table 5]}

\subsection{Education and age}

In 2016, less educated patients asked significantly more practical questions (mostly financial and requests for services) than higher educated patients (Table 4). Less educated patients also tended to ask fewer medical questions and slightly less questions in total than higher/university educated patients (not significant). In addition, older patients asked significantly less social context questions than younger patients (see Table 4).

\subsection{The nature of complaints}

Patients with a complaint in ICPC chapter 5 (Psychological diseases and Social problems) asked significantly more psychosocial questions (see Table 4) than patients with a complaint in other ICPC chapters. 
Meijers, M.C., Potappel, A., Kloek, C. Hartman, T. olde, Spreeuwenberg, P., Dulmen, S. van, Noordman, J. Patient Education and Counseling: 2020, 103(6), p. 1168-1175

\section{Discussion and conclusion}

\subsection{Discussion}

This study aimed to gain insight into patient participation in general practice by examining if and how patients' question-asking behaviour has changed over time (2007-2016). As a main result we found that patients' question-asking behaviour has decreased in 2016 compared to 2007, while the average length of consultations has increased. Furthermore, the type of question-asking behaviour changed significantly: in particular medical questions decreased while practical (mainly financial, requests for services) questions increased. These findings are contrary to our expectations given current policy measures stressing the importance of patient participation. While it is no cause and effect, several factors could have influenced the associations we found. In everyday practice not all patients are capable or wish to be active participants in decision-making and, in addition, patient preferences for information do not necessarily translate into information seeking behaviour [24]. There is also evidence, in a study on cancer patients, that information seeking behaviour remained constant over time [25]. Still, this does not necessarily apply to the general practice where patients often present new complaints and general practitioners, time and again, supply information on all common medical conditions. The asking of fewer medical questions could also suggest the GP has already provided (more) medical information during the present or previous consultation. Next, patients' sociodemographic characteristics have been found to be important predictors of their willingness to participate in the medical encounter [13]. For example, women are more likely to discuss their feelings and emotions than men $[2,26]$, and older patients tend to ask less question than younger people $[27,28]$. The latter was confirmed in the present study with regard to social context questions only. In literature, higher educated patients are often found to be more assertive and inquisitive than patients with only secondary education or less $[27,29,30]$. In our own results, we saw that less educated patients asked significantly fewer medical questions and slightly less questions in total than higher/university educated patients. This might be associated with their literacy level, as literacy level is an important determinant of patients' participation in the medical encounter. Patients with low (health) literacy may be less able to respond to GPs' use of patientcentred communication approaches than adequately literate patients [31]. Patients may also feel reluctant to ask their GPs questions due to diminished feelings of self-efficacy or because they view the GP as the 'decision-maker' and are hesitant to express their opinions or to ask questions $[2,13]$. In general, because low (health) literate patients tend to ask fewer questions about their medical care, this may affect their ability to learn about their medical conditions and treatments [13]. Other strong predictors of patient participation seem to be situation-specific, namely the GP's communication style and the clinical setting [1,2]. In our study, consultations lasted significantly longer in 2016 than in 2007. Longer consultations provide more time for patients to ask questions or for GPs to provide (medical) information. The latter is in line with a study by Bensing et al. [15] who found that patients with hypertension were less active during consultations in 2002 compared to 1986 while GPs provided more medical information. In addition, this previous study concluded that over the years GPs have become more task-oriented and business-like, reflecting the emphasis on evidence-based medicine and protocolized care. Patients talked substantially less about what was bothering them and asked fewer biomedical questions. This is also in agreement with our study. Nowadays, it seems that GPs' task-oriented, business-like communication pattern has even expanded, as patients ask less questions and visit their GP more for practical, non-medical questions.

While the above mentioned might explain why patients' question-asking behaviour in the medical consultation is low, it does not explain the decrease in patients' level of activity - in terms of question-asking - compared to eight years ago. More specifically, our findings turn into complete opposite directions than the policy measures in our Dutch healthcare system actually aim for: the amount of medical, psychosocial and social questions decreased, lifestyle and opinion questions 
Meijers, M.C., Potappel, A., Kloek, C. Hartman, T. olde, Spreeuwenberg, P., Dulmen, S. van, Noordman, J. Patient Education and Counseling: 2020, 103(6), p. 1168-1175

remained similar, while practical questions increased. In subsequent years, the Dutch healthcare system has been subject to several changes. Under the Health Insurance Act (Zorgverzekeringswet), statutory coverage is now provided by private insurers, to offer patient choice and managed competition. Moreover, the cornerstone of the present policy is an emphasis on people's personal responsibility for healthy lifestyles [14].

Even more remarkably, we found that especially less educated people asked more practical type of questions than did higher educated people. Several questions come to mind: What is the influence of a GP communication style? And did GPs' task-oriented, business-like role has extend too much? And could this be a consequence of the emphasis on evidence-based medicine and protocolized care? Or a result of the so called 'participation society' (i.e. Dutch healthcare reforms) where patients, especially less educated people, lean on their GP when a social network of their own is absent to fall back on? And should this all be a task of the GP? Further research is necessary to answer these questions, draw conclusions and to look more in-depth into the nature of nonmedical questions and problems patients face when visiting their GPs, and subsequently the (preferred) role of the GP and their time available.

\subsection{Strengths and limitations}

An important strength of this study is that we used real-life video-recorded consultations collected during two time periods. Furthermore, neither the GPs nor the patients were aware of the fact that patients' question-asking behaviour was our focus of interest. However, some limitations are worth noting. Firstly, patient participation is not uniquely based on question-asking behaviour and an active patient does not necessarily ask many questions. Patient participation is also about patients who, for example, are making remarks or expressing their feelings, concerns or opinions $[1,2]$ Because we do not consider question-asking and participation as synonymous, our finding of a decrease in patients' question-asking behaviour is no undisputed evidence for a decrease in patient participation. Moreover, this study only focused on patients' question-asking and no other forms of expression. Also, with regard to our main findings, the categories medical questions and practical questions had the lowest inter-rater agreement. This can be explained by the fact that those were the categories who had the tendency to overlap at some point (for example: "do I have to take this medicine every day before breakfast"?). Secondly, we only focused on the patient perspective. However, with regard to the complexity of the dialogue between patients and GPs, focusing on the patient alone may not produce long term benefits for patients. Successful consultations require that patients and GPs agree on the nature of the problem and what should be done [2]. Future research should investigate whether improving mutual understanding of the problem through patient question-asking could impose opportunities for more effective patient participation and could also include patients' wishes or needs. For example, GPs probably could continue facilitating patient involvement by more frequently using partnership-building and supportive communication $[13,28]$. Finally, we did not take the region of the GP's practice into account and if it was a first or follow-up consultation between patient and GP because that was unknown, which could have influenced patients' question-asking behaviour. With regard to the localization of the GP practices, in the Netherlands, this is not likely to have an effect on GPs' communication style. GP practices are governed by national guidelines and GPs' vocational training is quite similar throughout the Netherlands, including attending to communication skills. Differences in vocational training over time were unknown.

\subsection{Conclusion}

Contrary to our expectations, patients' question-asking has decreased in the last decade, while the total consultation length has increased and the type of question-asking behaviour changed. In particular medical questions decreased while 'practical questions increased, specifically for patients 
with lower education. It seems that GPs' task-oriented, business-like role expanded over the years, since nowadays patients ask their GP more practical, non-medical questions.

\subsection{Practice implications}

Our findings show that patients ask GPs less questions in general, and more practical type of questions at the expense of medical questions. In their education and profession GPs mainly focus on evidence-based medicine and protocolized care with providing medical-technical information [32]. Of course, this is very important and it, ideally, combines available research evidence, physician expertise, and the patient's wishes. However, from our study it seems that patients feel the need to ask for another, more expanded, role of the GP as well; a GP who leaves room for patient's practical (non-medical), mainly financial questions and requests for services. As mentioned before, GPs probably could continue facilitating patient involvement by more frequently using partnershipbuilding and supportive communication, specifically for less educated patients. Still, it is questionable whether or not this should all be the task of a GP, which may be worthwhile to discuss not only on a policy level but also within the GP-patient encounter.

\section{Funding}

This work was supported by the Dutch Ministry of Health, Welfare and Sport; and ZonMw [grant number 839110010].

\section{CRediT authorship contribution statement}

Maartje C. Meijers: Conceptualization, Methodology, Writing - original draft, Writing - review \& editing, Validation. Amy Potappel: Methodology, Writing - review \& editing. Corelien Kloek: Methodology, Writing - review \& editing. Tim olde Hartman: Writing - review \& editing. Peter Spreeuwenberg: Methodology, Formal analysis. Sandra van Dulmen: Writing - review \& editing, Validation. Janneke Noordman: Conceptualization, Methodology, Writing - review \& editing, Validation.

\section{Declaration of Competing Interest}

None

\section{Acknowledgement}

We would like to thank the patients and GPs who participated in the studies.

\section{Appendix A. Supplementary data}

Supplementary material related to this article can be found, in the online version, at doi:https://doi.org/10.1016/j.pec.2020.01.016.

\section{References}

[1] Y. Longtin, H. Sax, L.L. Leape, S.E. Sheridan, L. Donaldson, D. Pittet, Patient participation: current knowledge and applicability to patient safety, Mayo Clin. Proc. 85 (2010) 53-62, doi:http://dx.doi.org/10.4065/mcp.2009.0248. 
Meijers, M.C., Potappel, A., Kloek, C. Hartman, T. olde, Spreeuwenberg, P., Dulmen, S. van, Noordman, J. Patient Education and Counseling: 2020, 103(6), p. 1168-1175

[2] J. Gruman, M.H. Rovner, M.E. French, et al., From patient education to patient engagement: implications for the field of patient education, Patient Educ. Couns. 78 (2010) 350-356, doi:http://dx.doi.org/10.1016/j.pec.2010.02.002.

[3] A. Victoor, (How) Do Patients Choose a Healthcare Provider? CPI Wöhrmann Print Service, Zutphen, 2015.

[4] R.L. Street Jr, Active patients as powerful communicators, in: W.P. Robinson, H. Giles (Eds.), The New Handbook of Language and Social Psychology, John Wiley \& Sons Ltd., Chichester (UK), 2001, pp. 541-560.

[5] Cegala D.J. Cegala, R.L. Street Jr, C.R. Clinch, The impact of patient participation on physicians' information provision during a primary care medical interview, Health Commun. 21 (2007) 177185, doi:http://dx.doi.org/10.1080/10410230701307824.

[6] R.L. Street Jr, G. Makoul, N.K. Arora, R.M. Epstein, How does communication heal? Pathways linking clinician-patient communication to health outcomes, Patient Educ. Couns. 74 (2009) 295301, doi:http://dx.doi.org/10.1016/j. pec.2008.11.015.

[7] S.J. Griffin, A.L. Kinmonth, M.W. Veltman, S. Gillard, J. Grant, M. Stewart, Effect on healthrelated outcomes of interventions to alter the interaction between patients and practitioners: a systematic review of trials, Ann. Fam. Med. 2 (2004) 595-608, doi:http://dx.doi.org/10.1370/afm.142.

[8] R.L. Street Jr, B. Millay, Analyzing patient participation in medical encounters, Health Commun. 13 (2001) 61-73, doi:http://dx.doi.org/10.1207/S15327027HC1301_06.

[9] Gordon H.S, R.L. Street Jr, B.F. Sharf, J. Souchek, Racial differences in doctors' informationgiving and patients' participation, Cancer 107 (2006) 1313-1320, doi:http://dx.doi.org/10.1002/cncr.22122.

[10] D.J. Cegala, R.L. Street Jr, C.R. Clinch, The impact of patient participation on physicians' information provision during a primary care medical interview, Health Commun. 21 (2007) 177185, doi:http://dx.doi.org/10.1080/10410230701307824.

[11] R.L. Kravitz, R.M. Epstein, M.D. Feldman, C.E. Franz, R. Azari, M.S. Wilkes, et al., Influence of patients' requests for direct-to-consumer advertised antidepressants: a randomized controlled trial, J. Amer. Med. Assoc. 293 (2005) 1995-2002, doi:http://dx.doi.org/10.1001/jama.293.16.1995.

[12] R.L. Street Jr, E. Krupat, R.A. Bell, R.L. Kravitz, P. Haidet, Beliefs about control in the physicianpatient relationship, J. Gen. Intern. Med. 18 (2003) 609-616, doi: http://dx.doi.org/10.1046/j.15251497.2003.20749.x.

[13] M.G. Katz, T.A. Jacobson, E. Veledar, S. Kripalani, Patient literacy and questionasking behavior during the medical encounter: a mixed-methods analysis, J. Gen. Intern. Med. 22 (2007) 782786, doi:http://dx.doi.org/10.1007/s11606- 007-0184-6.

[14] J. Wammes, P. Jeurissen, G. Westert, M. Tanke, The Dutch Health System 2014, Radboud University Medical Center, 2014. Accessed 12.01.2019 https://international.commonwealthfund.org/countries/netherlands/.

[15] J.M. Bensing, F. Tromp, S. van Dulmen, A. van den Brink-Muinen, W. Verheul, F.G. Schellevis, Shifts in doctor-patient communication between 1986 and 2002, BMC Fam. Pract. 7 (2006) 62, doi:http://dx.doi.org/10.1186/1471-2296-7-62.

[16] J. Houwen, P.L. Lucassen, H.W. Stappers, P.J. Assendelft, S. van Dulmen, Medically unexplained symptoms: the person, the symptoms and the dialogue, Fam. Pract. 34 (2017) 245251, doi:http://dx.doi.org/10.1093/fampra/cmw132.

[17] J. Noordman, P. Verhaak, I. van Beljouw, S. van Dulmen, Consulting room computers and their effect on general practitioner-patient communication, Fam. Pract. 27 (2010) 644-651, doi:http://dx.doi.org/10.1093/fampra/cmq058. 
Meijers, M.C., Potappel, A., Kloek, C. Hartman, T. olde, Spreeuwenberg, P., Dulmen, S. van, Noordman, J. Patient Education and Counseling: 2020, 103(6), p. 1168-1175

[18] E. Arborelius, T. Timpka, In what way may videotapes be used to get significant information about the patient-physician relationship? Med. Teach. 12 (1990) 197-208 https://doi.org/10.1177\%2F140349489202000405.

[19] R.A. Verheij, C.E. van Dijk, H. Abrahamse, R. Davids, H. van den Hoogen, J. Braspenning, T. van Althuis, Landelijk Informatienetwerk Huisartsenzorg. Feiten en cijfers over huisartsenzorg in Nederland. [Netherlands Information Network of General Practice: facts and figures of general practice in the Netherlands]. NIVEL/WOK, Utrecht/Nijmegen. (2008).

[20] A.J. Viera, J.M. Garrett, Understanding interobserver agreement: the kappa statistic, Fam. Med. 37 (2005) 360-363.

[21] D.L. Roter, The Roter Interaction Analysis System (RIAS) Coding Manual, School of Hygiene and Public Health, Johns Hopkins University, Baltimore, Md, 1991.

[22] D.L. Roter, S. Larson, The Roter interaction analysis system (RIAS): utility and flexibility for analysis of medical interactions, Patient Educ. Couns. 46 (2002) 243-251, doi:http://dx.doi.org/10.1016/S0738-3991(02)00012-5.

[23] Stata, Stata Statistical Software. Relesae 14.ed. 4905 Lakeway Drive, College Station, TX 77845 USA, 2015.

[24] C.L. Arnold, J.J. Coran, M.G. Hagen, Revisiting patient communication training: an updated needs assessment and the AGENDA model, Patient Educ. Couns. 88 (2012) 399-405, doi:http://dx.doi.org/10.1016/j.pec.2012.06.026.

[25] T. Wieldraaijer, L.A.M. Duineveld, W.A. Bemelman, H.C.P.M. van Weert, J. Wind, Information needs and information seeking behaviour of patients during follow-up of colorectal cancer in the Netherlands, J. Cancer Surviv. 13 (2019) 603-610, doi:http://dx.doi.org/10.1007/s11764-01900779-5.

[26] K.D. Bertakis, The influence of gender on the doctor-patient interaction, Patient Educ. Couns. 76 (2009) 356-360, doi:http://dx.doi.org/10.1016/j.pec.2009.07.022.

[27] S. Willems, S. de Maesschalck, M. Deveugele, A. Derese, J. de Maeseneer, Socioeconomic status of the patient and doctor-patient communication: does it make a difference? Patient Educ. Couns. 56 (2005) 139-146, doi:http://dx.doi.org/10.1016/j.pec.2004.02.011.

[28] R.C. Maly, Y. Umezawa, B. Leake, R.A. Silliman, Determinants of participation in treatment decision-making by older breast cancer patients, Breast Cancer Res. Treat. 85 (2004) 201-209, doi:http://dx.doi.org/10.1002/1097-0142 (19951201)76:11\%3C2275::AIDCNCR2820761115\%3E3.0.CO;2-S.

[29] L.A. Siminoff, G.C. Graham, N.H. Gordon, Cancer communication patterns and the influence of patient characteristics: disparities in information-giving and affective behaviors, Patient Educ. Couns. 62 (2006) 355-360, doi:http://dx.doi.org/10.1016/j.pec.2012.02.018.

[30] R.L. Street Jr, H. Gordon, P. Haidet, Physicians' communication and perceptions of patients: is it how they look, how they talk, or is it just the doctor? Soc. Sci. Med. 65 (2007) 586-598 https://dx.doi.org/10.1007\% 2Fs11606-010-1453-3.

[31] H.J. Aboumatar, K.A. Carson, M.C. Beach, D.L. Roter, L.A. Cooper, The impact of health literacy on desire for participation in healthcare, medical visit communication, and patient reported outcomes among patients with hypertension, J. Gen. Intern. Med. 28 (2013) 1469-1476, doi:http://dx.doi.org/10.1016/j.ijnss.2018.06.001.

[32] L.A. Maggio, Educating physicians in evidence based medicine: current practices and curricular strategies, Perspect. Med. Educ. 5 (2016) 358-361, doi:http://dx.doi.org/10.1007/s40037-0160301-5. 
Meijers, M.C., Potappel, A., Kloek, C. Hartman, T. olde, Spreeuwenberg, P., Dulmen, S. van, Noordman, J. Patient Education and Counseling: 2020, 103(6), p. 1168-1175

\section{Tables and figures}

Figure 1 Flowchart of inclusion of study participants.

* the amount of missing values is large because records that were lacking either educational level or consultation time had to be removed in order for a fully-fledged analysis.

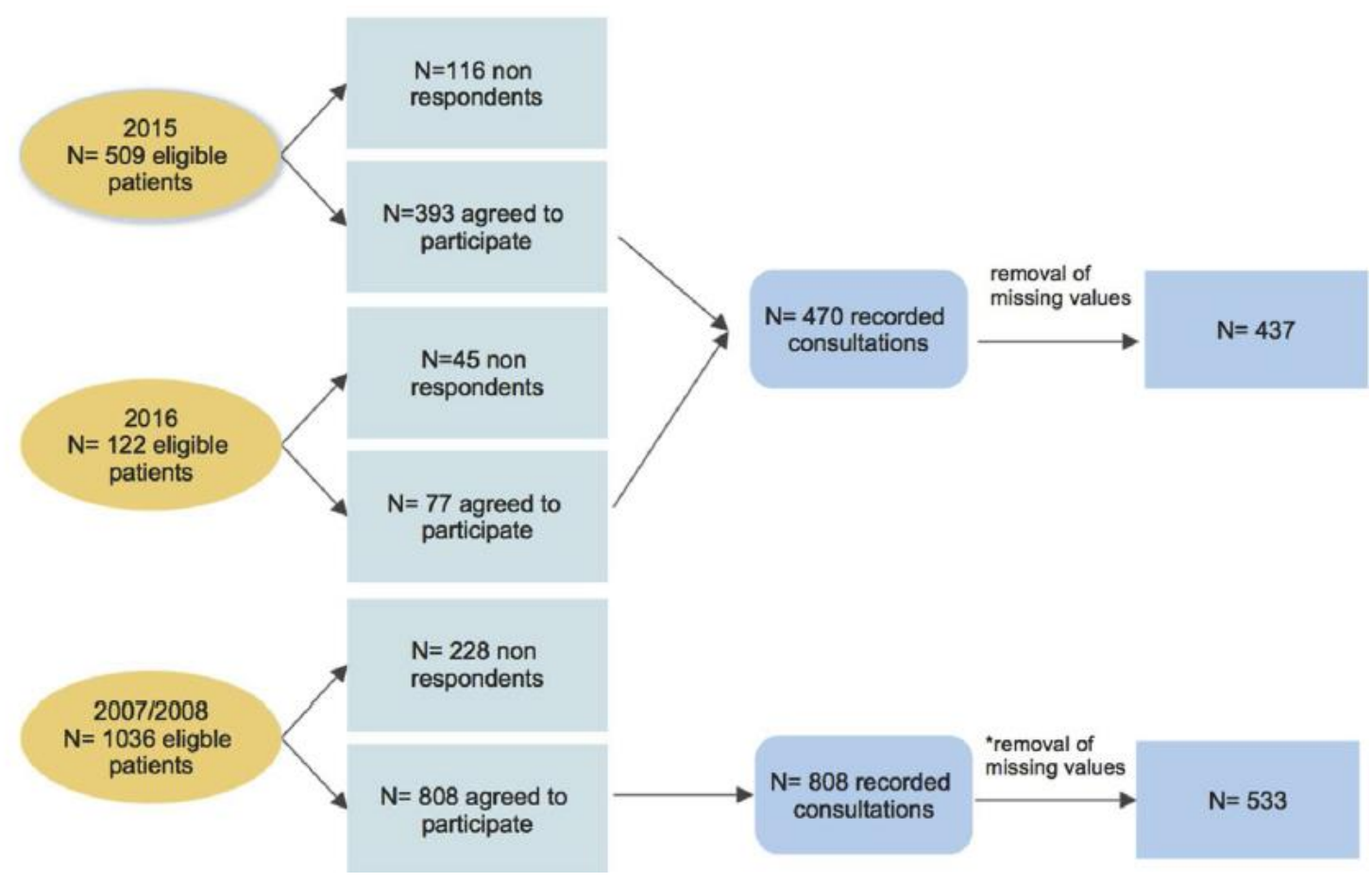

Table 1 Inter-rater agreement (\%) between the three observers from observations of patients' question-asking behaviour.

\begin{tabular}{lll}
\hline & $\mathrm{N}=48$ \\
\cline { 2 - 3 } Type of question & Agreement (\%) & Range (\%) \\
\hline Medical condition / therapeutic regimen & 70.83 & $68.75-77.08$ \\
Psychosocial feelings & 95.83 & $93.75-100$ \\
Social context & 94.44 & $93.75-95.83$ \\
Lifestyle & 94.45 & $91.67-100$ \\
Asks for opinion & 77.78 & $68.75-83.33$ \\
Practical & 66.67 & $56.25-81.25$ \\
\hline
\end{tabular}


Meijers, M.C., Potappel, A., Kloek, C. Hartman, T. olde, Spreeuwenberg, P., Dulmen, S. van, Noordman, J. Patient Education and Counseling: 2020, 103(6), p. 1168-1175

Table 2 Aggregation of ICPC codes into 5 relevant chapters.

Aggregation of ICPC codes into 5 relevant chapters.

\begin{tabular}{|c|c|c|c|c|}
\hline & Chapter ICPC & Complaints concerning (examples that were observed) & Amount $(\mathrm{n})$ & Percentage (\%) \\
\hline \multirow[t]{6}{*}{1} & A & General and unspecified diseases (fatigue, generalized pain) & & \\
\hline & $\mathrm{F}$ & Eyes (conjunctivitis, corpus alienum) & & \\
\hline & $\mathrm{H}$ & Ears (otitis media acuta, impaired hearing) & & \\
\hline & $\mathrm{SR}$ & Dermatological diseases (fungus, eczema) & & \\
\hline & & Respiratory tract (coughing, pneumoniae) & & \\
\hline & & & 323 & 33 \\
\hline \multirow[t]{5}{*}{2} & B & Blood and lymphatic system (vitamin deficiencies, enlarged lymph nodes) & & \\
\hline & $\mathrm{K}$ & Circulatory system (palpitations, hypertension) & & \\
\hline & $\mathrm{T}$ & Endocrine, metabolic and nutritional (Thyroid) & & \\
\hline & D & Gastro-intestinal tract (acid reflux, hemorrhoids) & & \\
\hline & & & 236 & 24 \\
\hline \multirow[t]{3}{*}{3} & L & Musculoskeletal system (back pain, knee trauma) & & \\
\hline & $\mathrm{N}$ & Neurological system (migraine, tension headache) & & \\
\hline & & & 251 & 26 \\
\hline \multirow[t]{5}{*}{4} & $\mathrm{U}$ & Urinary tract diseases (urine tract infections) & & \\
\hline & W & Pregnancy, childbirth, family planning (oral anticonception) & & \\
\hline & $\mathrm{X}$ & Female genital and breast (dysmenorrhea) & & \\
\hline & $\mathrm{Y}$ & Male genital (sterilization) & & \\
\hline & & & 77 & 8 \\
\hline \multirow[t]{3}{*}{5} & $\mathrm{P}$ & Psychological diseases (depression, nervousness) & & \\
\hline & $\mathrm{Z}$ & Social problems & & \\
\hline & & & 83 & 9 \\
\hline
\end{tabular}

Table 3 Sociodemographic and consultation characteristics of the study sample.

\begin{tabular}{|c|c|c|c|c|c|c|}
\hline \multirow{3}{*}{$\begin{array}{l}\text { Patient characteristics } \\
\text { Age years }\end{array}$} & \multicolumn{3}{|c|}{$2007-2008(N=533)$} & \multicolumn{3}{|c|}{$2015-2016(\mathrm{~N}=437)$} \\
\hline & Mean & SD & Range & Mean & SD & Range \\
\hline & 52.4 & 17.0 & $18-87$ & 54.5 & 17.6 & $18-90$ \\
\hline \multirow[t]{2}{*}{ Sex Male } & $\mathrm{N}$ & $\%$ & & $\mathrm{~N}$ & $\%$ & \\
\hline & 211 & 40 & & 186 & 43 & \\
\hline ICPC chapters & $\mathrm{N}$ & $\%$ & & $\mathrm{~N}$ & $\%$ & \\
\hline 1 & 181 & 34 & & 142 & 32 & \\
\hline 2 & 131 & 25 & & 105 & 24 & \\
\hline 3 & 148 & 28 & & 103 & 24 & \\
\hline 4 & 42 & 8 & & 35 & 8 & \\
\hline 5 & 31 & 6 & & 52 & 12 & \\
\hline Education & $\mathrm{N}$ & $\%$ & & $\mathrm{~N}$ & $\%$ & \\
\hline None (yet) & 29 & 5 & & 9 & 2 & \\
\hline Primary & 77 & 14 & & 195 & 45 & \\
\hline Secondary & 312 & 59 & & 80 & 18 & \\
\hline Higher/university & 115 & 22 & & 153 & 35 & \\
\hline \multicolumn{7}{|l|}{ GP } \\
\hline characteristics & 2007-2 & & & 2015-2 & & \\
\hline \multirow[t]{2}{*}{ Age years } & Mean & SD & Range & Mean & SD & Range \\
\hline & 51.5 & 5.6 & $40-62$ & 47.4 & 10.9 & $31-69$ \\
\hline Sex & $\mathrm{N}$ & $\%$ & & $\mathrm{~N}$ & $\%$ & \\
\hline Male & 26 & 65 & & 12 & 43 & \\
\hline \multicolumn{7}{|c|}{ Consultation characteristics } \\
\hline $2007-2008(N=533)$ & & & & 2015-2 & & \\
\hline Duration ${ }^{*}$ & Mean & SD & & Mean & SD & \\
\hline in minutes & 10.7 & 4.9 & & 13.4 & 5.9 & \\
\hline Type of questions & Mean & SD & Range & Mean & SD & Range \\
\hline Medical $^{*}$ & 3.2 & 3.7 & $0-25$ & 1.5 & 1.9 & $0-12$ \\
\hline Psychosocial & 0.1 & 0.3 & $0-2$ & 0.0 & 0.1 & $0-1$ \\
\hline Social context & 0.1 & 0.4 & $0-3$ & 0.0 & 0.2 & $0-3$ \\
\hline Lifestyle & 0.0 & 0.2 & $0-3$ & 0.0 & 0.2 & $0-3$ \\
\hline Asks for opinion & 0.3 & 0.8 & $0-8$ & 0.3 & 0.7 & $0-5$ \\
\hline Practical $^{*}$ & 0.1 & 0.6 & $0-5$ & 0.9 & 1.2 & $0-6$ \\
\hline Total $^{*}$ & 3.8 & 4.0 & $0-30$ & 2.8 & 2.8 & $0-18$ \\
\hline
\end{tabular}


Meijers, M.C., Potappel, A., Kloek, C. Hartman, T. olde, Spreeuwenberg, P., Dulmen, S. van, Noordman, J. Patient Education and Counseling: 2020, 103(6), p. 1168-1175

Table 4 Patients' question-asking behaviour over time and associations with medical and demographic characteristics.

\begin{tabular}{|c|c|c|c|c|c|c|c|c|c|c|c|c|c|c|c|c|c|c|c|}
\hline \multirow[t]{2}{*}{ Variable } & \multirow[t]{2}{*}{ Category } & \multicolumn{3}{|c|}{ Medical } & \multicolumn{3}{|c|}{ Psychosocial } & \multicolumn{3}{|l|}{ Social } & \multicolumn{3}{|c|}{ Lifestyle } & \multicolumn{3}{|c|}{ Opinion } & \multicolumn{3}{|c|}{ Practical } \\
\hline & & Coef. & SD & $95 \% \mathrm{CI}$ & Coef. & SD & $95 \% \mathrm{Cl}$ & Coef. & SD & $95 \% \mathrm{CI}$ & Coef. & SD & $95 \% \mathrm{CI}$ & Coef. & SD & $95 \% \mathrm{CI}$ & Coef. & SD & $95 \% \mathrm{CI}$ \\
\hline Intercept (model 1) & & 1.66 & 0.14 & $\begin{array}{l}1.38- \\
1.94\end{array}$ & -3.2 & .322 & $\begin{array}{l}-3.85 \\
--2.58\end{array}$ & -2.77 & .27 & $\begin{array}{l}-3.29- \\
-2.24\end{array}$ & -3.91 & .388 & $\begin{array}{l}-4.68 \\
--3.15\end{array}$ & -1.65 & .15 & $\begin{array}{l}-1.95- \\
-1.35\end{array}$ & -3.10 & .22 & $\begin{array}{l}-3.50- \\
2.64\end{array}$ \\
\hline Year (model 3) & $\begin{array}{l}2007 \\
2016\end{array}$ & $\begin{array}{l}r e f \\
- \\
1.10\end{array}$ & $\begin{array}{l}r e f \\
0.22\end{array}$ & $\begin{array}{l}\text { ref } \\
-1.51 \\
--.6\end{array}$ & $\begin{array}{l}r e f \\
-3.02\end{array}$ & $\begin{array}{l}\text { ref } \\
.71\end{array}$ & $\begin{array}{l}\text { ref } \\
-4.4- \\
-1 .\end{array}$ & $\begin{array}{l}\text { ref } \\
-2.72\end{array}$ & $\begin{array}{l}r e f \\
.67\end{array}$ & $\begin{array}{l}\text { ref } \\
-4.05- \\
-1\end{array}$ & $\begin{array}{l}r e f \\
-.42\end{array}$ & $\begin{array}{l}\text { ref } \\
.45\end{array}$ & $\begin{array}{l}\text { ref } \\
-1.31=\end{array}$ & $\begin{array}{l}\text { ref } \\
-.16\end{array}$ & $\begin{array}{l}r e f \\
.26\end{array}$ & $\begin{array}{l}\text { ref } \\
-.66-.3\end{array}$ & $\begin{array}{l}r e f \\
3.02\end{array}$ & $\begin{array}{l}r e f \\
.29\end{array}$ & $\begin{array}{l}\text { ref } \\
2.45-3 .\end{array}$ \\
\hline Age of patients & & .01 & .00 & $\begin{array}{l}-.00 \\
-.0\end{array}$ & -.02 & .013 & $-.05-.0$ & -.03 & .01 & $\begin{array}{l}-.05- \\
-.0\end{array}$ & -.00 & .01 & $-.03-.0$ & -.00 & .00 & $\begin{array}{l}-.011- \\
.0\end{array}$ & .01 & .01 & $\begin{array}{l}-0.00- \\
.0\end{array}$ \\
\hline \multirow[t]{2}{*}{ Sex of patients } & Female & ref & ref & ref & ref & ref & ref & ref & ref & ref & ref & ref & ref & ref & ref & ref & ref & ref & ref \\
\hline & Male & .01 & .16 & -.31 & .44 & .44 & $-.43-1$ & -.57 & .35 & $\begin{array}{l}-1.26- \\
.1\end{array}$ & .10 & .42 & $-.72-.9$ & -.26 & .18 & $-.62-.0$ & .03 & .19 & $-.35-.4$ \\
\hline Age of GPs & & .01 & .01 & $\begin{array}{l}-.01- \\
.0\end{array}$ & -.00 & .03 & $-.07-.0$ & -0.0 & .02 & $-.06-.0$ & .07 & .03 & $.02-.1$ & -.01 & .01 & $-.03-.0$ & .01 & .01 & $-.02-.0$ \\
\hline \multirow[t]{2}{*}{ Sex of GPs } & Female & .03 & .20 & $\begin{array}{l}-.37 \\
-.4\end{array}$ & ref & ref & ref & ref & ref & ref & ref & ref & ref & ref & ref & ref & ref & ref & ref \\
\hline & Male & & & & .41 & .42 & $-.42-1$. & -.36 & .41 & $-1.2-.4$ & .54 & .44 & $-.32-1$ & -.20 & .24 & $-69-.2$ & -.04 & .25 & $-.54-.4$ \\
\hline \multirow[t]{4}{*}{ Education } & $\begin{array}{l}\text { None } \\
\text { (yet) }\end{array}$ & .00 & .46 & $\begin{array}{l}-.87- \\
.9\end{array}$ & .23 & .90 & $-1.5-1$ & 1.17 & .70 & $-.20-2$ & - & - & - & -.16 & .48 & $\begin{array}{l}-1.09- \\
.7\end{array}$ & .11 & .58 & $\begin{array}{l}-1.02- \\
1 .\end{array}$ \\
\hline & Primary & -.14 & .21 & $\begin{array}{l}-.55- \\
.2\end{array}$ & .25 & .60 & $-.94-1$. & .19 & .60 & $-.97-1$. & .05 & .51 & $-.94-1$ & -1.12 & .24 & $-.58-.3$ & .51 & .23 & $.06-.9$ \\
\hline & Secondary & .04 & .21 & $\begin{array}{l}-.38- \\
.4\end{array}$ & -.29 & .47 & $\begin{array}{l}-1.21 \\
-.6\end{array}$ & .18 & .43 & $-.67-1$ & -.34 & .50 & $\begin{array}{l}-1.38- \\
.5\end{array}$ & -.41 & .23 & $-.86-.0$ & .29 & .26 & $-.22-.8$ \\
\hline & $\begin{array}{l}\text { Higher/ } \\
\text { university }\end{array}$ & ref & ref & ref & ref & ref & ref & ref & ref & ref & ref & ref & ref & ref & ref & ref & ref & ref & ref \\
\hline \multirow{5}{*}{$\begin{array}{l}\text { Nature of } \\
\text { complaint (ICPC } \\
\text { chapters) }\end{array}$} & 1 & ref & ref & ref & ref & ref & ref & ref & ref & ref & ref & ref & ref & ref & ref & ref & ref & ref & ref \\
\hline & 2 & .23 & .21 & $\begin{array}{l}-.20- \\
.6\end{array}$ & .06 & .59 & $-1.1-1$ & -.02 & .50 & $-1.0-.9$ & 1.01 & .50 & $.04-1$ & -.06 & .24 & $-.52-.4$ & .39 & .25 & $-.10-. .8$ \\
\hline & 3 & -.08 & .20 & $\begin{array}{l}-.49- \\
.3\end{array}$ & -.11 & .58 & $\begin{array}{l}-1.26 \\
-1 .\end{array}$ & .31 & .44 & $-.56-1$. & -.29 & .65 & $\begin{array}{l}-1.57- \\
.9\end{array}$ & -.10 & .24 & $-.56-.3$ & .06 & .26 & $-.44-$ \\
\hline & 4 & .12 & .32 & $\begin{array}{l}-.50- \\
.7\end{array}$ & .02 & .76 & $\begin{array}{l}-1.48- \\
1 .\end{array}$ & -.57 & .83 & $\begin{array}{l}-2.2 \\
-1 .\end{array}$ & -.54 & 1.11 & $\begin{array}{l}-2.71- \\
1 .\end{array}$ & .29 & .33 & $-.36-.9$ & .32 & .37 & $-40-1$ \\
\hline & 5 & -.69 & .29 & $\begin{array}{l}- \\
1.26- \\
-.1\end{array}$ & 1.63 & .59 & $.48-2$ & .98 & .59 & $-.17-2$ & .06 & .77 & $-1.44-1$ & -.66 & .37 & $\begin{array}{l}-1.40- \\
.0\end{array}$ & .55 & .34 & $-.13-1$ \\
\hline $\begin{array}{l}\text { Consultation } \\
\text { duration }\end{array}$ & $\begin{array}{l}2007 \\
2015\end{array}$ & $\begin{array}{l}\text { ref } \\
.00\end{array}$ & $\begin{array}{l}\text { ref } \\
.00\end{array}$ & $\begin{array}{l}\text { ref } \\
.00-.0\end{array}$ & $\begin{array}{l}\text { ref } \\
.00\end{array}$ & $\begin{array}{l}\text { ref } \\
.00\end{array}$ & $\begin{array}{l}\text { ref } \\
.00-.0\end{array}$ & $\begin{array}{l}\text { ref } \\
.00\end{array}$ & $\begin{array}{l}\text { ref } \\
.00\end{array}$ & $\begin{array}{l}\text { ref } \\
0.00-.0\end{array}$ & $\begin{array}{l}\text { ref } \\
.00\end{array}$ & $\begin{array}{l}\text { ref } \\
.00\end{array}$ & $\begin{array}{l}\text { ref } \\
0.00-.0\end{array}$ & $\begin{array}{l}\text { ref } \\
.00\end{array}$ & $\begin{array}{l}\text { ref } \\
.00\end{array}$ & $\begin{array}{l}\text { ref } \\
.0-.0\end{array}$ & $\begin{array}{l}\text { ref } \\
.00\end{array}$ & $\begin{array}{l}\text { Ref } \\
.00\end{array}$ & $\begin{array}{l}\text { ref } \\
0.00-0\end{array}$ \\
\hline
\end{tabular}


Meijers, M.C., Potappel, A., Kloek, C. Hartman, T. olde, Spreeuwenberg, P., Dulmen, S. van, Noordman, J. Patient Education and Counseling: 2020, 103(6), p. 1168-1175

Table 5 Type of questions illustrated by quotes.

Type of questions illustrated by quotes.

\begin{tabular}{ll}
\hline Type of question & Quotes \\
\hline Medical condition/therapeutic regimen & P (3):" I have used Naproxen (medication) about 5 to 6 times a month, is that bad?" \\
P (10): “And what exactly is the difference with an orthopedist?" \\
Psychosocial feelings & GP: "And can you still handle all this?" P (11): "What if I told you no, what would you do?" \\
Social context & GP: "Well, then maybe we can bring in some help?" \\
& P (11): "Well, my wife doesn't want that. So no, it's fine. Leave it like that. Otherwise, can't you come over and \\
& talk to her next week?" \\
Lifestyle & P (13): "And what can I do about it then? Does that also have something to do with eating liquid fats and stuff? \\
& What is the advice for that?" \\
Ask for opinion & P (2): "What do you think, could the drugs I take against low blood pressure cause it?" \\
Practical (mainly financial and & P (1): "Can I just get saline from the pharmacy? \\
requests for services) & P (4): "And where should I pick up such a (heart) box?" \\
\hline
\end{tabular}

$\mathrm{P}=$ Patient, $\mathrm{GP}=$ General Practitioner. 